\title{
2008s-02 \\ Is Emulation Good for You? The Ups and Downs of Rivalry
}

\author{
Daniel Leonard, Ngo Van Long
}

Série Scientifique
Scientific Series

\author{
Montréal \\ Janvier 2008
}

(C) 2008 Daniel Leonard, Ngo Van Long. Tous droits réservés. All rights reserved. Reproduction partielle permise avec citation du document source, incluant la notice (C).

Short sections may be quoted without explicit permission, if full credit, including $\mathbb{C}$ notice, is given to the source.
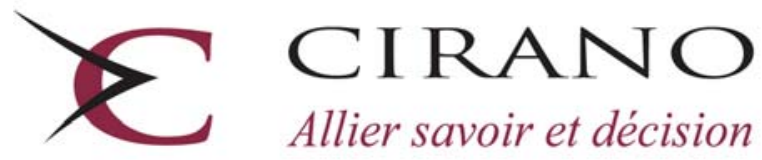

Allier savoir et décision

Centre interuniversitaire de recherche en analyse des organisations 


\section{CIRANO}

Le CIRANO est un organisme sans but lucratif constitué en vertu de la Loi des compagnies du Québec. Le financement de son infrastructure et de ses activités de recherche provient des cotisations de ses organisations-membres, d'une subvention d’infrastructure du Ministère du Développement économique et régional et de la Recherche, de même que des subventions et mandats obtenus par ses équipes de recherche.

CIRANO is a private non-profit organization incorporated under the Québec Companies Act. Its infrastructure and research activities are funded through fees paid by member organizations, an infrastructure grant from the Ministère du Développement économique et régional et de la Recherche, and grants and research mandates obtained by its research teams.

\section{Les partenaires du CIRANO}

\section{Partenaire majeur}

Ministère du Développement économique, de l’Innovation et de l’Exportation

\section{Partenaires corporatifs}

Alcan inc.

Banque de développement du Canada

Banque du Canada

Banque Laurentienne du Canada

Banque Nationale du Canada

Banque Royale du Canada

Banque Scotia

Bell Canada

BMO Groupe financier

Bourse de Montréal

Caisse de dépôt et placement du Québec

DMR Conseil

Fédération des caisses Desjardins du Québec

Gaz de France

Gaz Métro

Hydro-Québec

Industrie Canada

Investissements PSP

Ministère des Finances du Québec

Raymond Chabot Grant Thornton

State Street Global Advisors

Transat A.T.

Ville de Montréal

\section{Partenaires universitaires}

École Polytechnique de Montréal

HEC Montréal

McGill University

Université Concordia

Université de Montréal

Université de Sherbrooke

Université du Québec

Université du Québec à Montréal

Université Laval

Le CIRANO collabore avec de nombreux centres et chaires de recherche universitaires dont on peut consulter la liste sur son site web.

Les cahiers de la série scientifique (CS) visent à rendre accessibles des résultats de recherche effectuée au CIRANO afin de susciter échanges et commentaires. Ces cahiers sont écrits dans le style des publications scientifiques. Les idées et les opinions émises sont sous l'unique responsabilité des auteurs et ne représentent pas nécessairement les positions du CIRANO ou de ses partenaires.

This paper presents research carried out at CIRANO and aims at encouraging discussion and comment. The observations and viewpoints expressed are the sole responsibility of the authors. They do not necessarily represent positions of CIRANO or its partners. 


\title{
Is Emulation Good for You? The Ups and Downs of Rivalry
}

\author{
Daniel Leonard*, Ngo Van Long ${ }^{\dagger}$
}

\begin{abstract}
Résumé / Abstract
Nous étudions un phénomène d'émulation entre deux athlètes pour qui des objectifs sont axés par leur entraîneur. Cela conduit à un jeu stratégique entre les entraîneurs qui aboutit à un équilibre de Nash. Pour certaines valeurs des paramètres l'un joue une stratégie mixte tandis que l'autre joue une stratégie pure. On montre qu'il est très utile pour une athlète de se confronter à une autre athlète plus forte. Cela améliore la performance des deux. Si l'écart est trop grand, les conséquences sont très mauvaises pour les deux. Le vieil adage " Qui se ressemble s'assemble » se trouve validé.
\end{abstract}

Mots clés : Émulation

We model the emulation between two athletes whose goals are fixed by their coaches. The coaches in turn engage in a game of goal setting. We analyze the equilibriums of that game. For some range of parameter values, there are only mixed equilibriums, where one coach randomizes his goals while the other coach uses a pure strategy. We show that it is in an athlete's interest to have a stronger rival. Both athletes can gain if there is not a big gap between their ability levels. A very big gap, however, result in poorer performance of both.

Keywords: Emulation, Goal Setting

Codes JEL : I20,D01,D02

\footnotetext{
* Flinders Business School, Flinders University, Adelaide, 5001, Australia, email: Daniel.Leonard@flinders.edu.au

${ }^{\dagger}$ CIRANO and Department of Economics, McGill University, Montreal H3A 2T7, Canada, ngo.long@mcgill.ca
} 


\section{Introduction}

Emulation has long been recognized as an major force that shapes behaviour. Veblen (1924) defined emulation as "the stimulus of an invidious comparison which prompts us to outdo those with whom we are in the habit of classing ourselves." He claimed that "with the exception of the instinct for self-preservation, the propensity for emulation is probably the strongest and most alert and persistent of economic motives proper." According to Veblen "the motive that lies at the root of ownership is emulation; and the same motive of emulation continues active in the further development of institution to which it has given rise and in the development of all those features of the social structure which this institution of ownership touches." Emulation interacts with the instinct of workmanship: "Man is an agent seeking in every act an accomplishment of some concrete, objective, impersonal end. This aptitude or propensity may be called the instinct of workmanship. Whenever the circumstances of traditions of life lead to an habitual comparison of one person with another in point of efficiency, the instinct of workmanship works out in an emulative or invidious comparison of persons."

Educators have debated whether emulation should be encouraged. Rousseau was well known for his rejection of emulation. On the other hand, the use of ranking is often believed to stimulate performance. University departments are often asked to compare themselves with similar departments in other universities. (This practice, called "benchmarking," is being institutionalised at several major universities, including McGill university).

This paper explores some possible consequences of emulation. As a metaphor, we model the setting of goals for athletes by their coaches who know that their athletes may perform better with some suitably chosen degree of emulation. 


\section{The Basic Model}

Goal setting has been known to be a crucial element in achieving success, be it in sports, education, academia, or in the business world. Psychologists, researchers in sports science and management science have emphasized the importance of appropriate goal setting. (See Locke and Latham (1900a, 1990b), Hardy et al. (1986), Bell (1983), Botterill (1983), Cury and Sarrazin (1993), among others.) It is generally recognized that, subject to goals being realistic, performance increases as the goals become more difficult. This is known as "the hard goal effect" . (For empirical evidence in sports, see Beggs (1990), Cury and Sarrazin (1993).

Let us consider at first the simple case of an individual for whom a goal is already set. For example, parents set a school performance target (such as exam scores) for their children, a swimmer sets for himself a target of swimming across a river in $A$ seconds. There are other such instances in business and in sport; for instance a seamstress in Montreal might have been instructed to reach a target of $A$ shirts . The measurement of the goal $A$ is assumed to be smooth. The exact time in which a $400 \mathrm{~m}$ hurdle or a $100 \mathrm{~m}$ backstroke are run or swam do matter. One can think of a salesperson who has a set target of numbers of items sold or clients recruited. A bonus or a promotion might be the reward, and is linked to the size of the target.We attempt to capture these facets of the outcomes of competition in the following way. In our simple model we use a metric $A$ to measure the value of the target but we also characterize the outcome as success or failure. The probability of the agents, or athletes, achieving a set target depends on the effort level, denoted by $E$, on the target itself $A$, as well as other factors such as innate ability or self-confidence, denoted by $\lambda$. The higher the target, the less chance they will succeed, and the harder they strive, the more likely they are to meet their target. Clearly their perceived ability or 
self-confidence, $\lambda$, also improves their chances.

The prospect of success by an individual or a firm depend on their own efforts and abilities but might also depend on other factors, such as how they perceive their environment and others. Their probability of success, hence their performance is possibly influenced by it.. The salesperson does not operate in an isolated environment. There are other sales people in the same firm or perhaps in rival firms. They also have set targets which also influence their likelihood of success. The central premise of this paper is that the goals, or targets, for which an individual's rivals are striving have a real influence on the probability of success of that individual. Agents are aware of the targets set for other agents, and their values relative to their own target forms the basis of the process we refer to as 'emulation'.

Emulation, defined by the Webster's dictionary as "ambition or endeavor to equal or excel others (as in achievement)" is thus the main focus of the paper. It is important at this stage to clarify our use of the word 'emulation'. We use it in its common meaning. This concept has been investigateded in the social sciences from the time of Bentham (1811) and later Veblen ( 1924) as discussed above. It is also used by applied game theorists in the context of a strategic choice ( e.g. Dana (2005)) where emulation is akin to imitation. Other authors, particularly in the labor economics literature (e.g. Brown (1994)), see it as an incentive mechanism. While these enquiries are worthwile, we do not follow the same avenues in this paper. The concept of emulation that we use here is indeed more akin to the one used by experimental psychologists, although our purpose is entirely different. They conceive of emulation as an automatic process that originates in the brain of the subject; see for instance Thompson and Russell (2004), whereas analysts of industrial organization are more interested in the active process of choosing an emulation strategy as opposed to a differentiation strategy. In this paper we take mainly the latter view that emulation, that of a natural 
process that depends on other individuals' goals reative to one's own, but we attempt to enrich it by taking into account the manner in which goals are set and by whom, thereby allowing interaction among goal setters.

We first consider a single individual who, if her target is $A$, her effort $E$ and her ability $\lambda$, has the probability $p$ of achieving her goal

$$
p=P(E, A, \lambda)=\left[\frac{\lambda E}{\lambda E+\kappa A}\right]
$$

where $\kappa$ is a factor reflecting the strength of the challenge represented by the goal within this individual's environment. Here $E$ is non-negative, and $A, \lambda$ and $\kappa$ are positive real numbers. The probability is clearly bounded by 1 . It is an increasing function of $\lambda E$ and a decreasing function of $\kappa A$. The factors that shape $\kappa$ are examined in the next section.

We suppose that her objective is to maximize her expected utility of success net of effort cost:

$$
\max _{E \geq 0} W(E) \equiv P(E, A, \lambda) u(A)-b E
$$

where $b>0$ is her cost per unit of effort, and $u(A) \geq 0$ is her evaluation of the "prize" $A$, with $u(0)=0, u^{\prime}(A)>0$ and $u$ " $(A)<0$.

This formulation implies that either (i) the individual gets zero utility if she fails to achieve the set target $A$ (regardless of how "close" the actual performance is to the goal), or (ii) if the individual fails, she does not know how close she was to the goal. On the other hand the measurability of $A$ accounts for the measurability of many sporting records and sales targets.

We assume for simplicity that

$$
u(A)=A^{\beta} \text { where } 0<\beta<1
$$

Then the athlete's expected utility (net of effort cost) is

$$
W(A, E, \lambda)=\left[\frac{\lambda E}{\lambda E+\kappa A}\right] A^{\beta}-b E
$$


The athlete takes $A$ and $\kappa$ as given. She chooses $E$ to maximize $W$. The first order condition implies

$$
\lambda E^{*}(A, \lambda, \kappa)= \begin{cases}\kappa A\left[\left(\frac{\bar{A}}{A}\right)^{\frac{1-\beta}{2}}-1\right] & \text { if } A \leq \bar{A}(\lambda, \kappa) \equiv\left(\frac{\lambda}{b \kappa}\right)^{1 /(1-\beta)} \\ 0, & \text { if } A \geq \bar{A}(\lambda, \kappa)\end{cases}
$$

Clearly, $E^{*}(\bar{A}(\lambda, \kappa), \lambda, \kappa)=0$. The function $E^{*}(A, \lambda, \kappa)$ as given by (4) has a positive derivative at $A=0$ and a negative derivative at $A=\bar{A}(\lambda, \kappa)$. Thus it has an inverted U-shape if the equation $\partial E^{*} / \partial A=0$ has a unique solution, which is in fact the case. One interpretation is that if the coach sets a goal larger than $\bar{A}$, the athlete quits. This is a consequence of the universally accepted stronger convexity of costs (linear) over benefits (concave). It also reflects the fact that one cannot push people to ever greater heights of achievement by simply challenging them to do so.This inverted U-shape property is a theoretically and empirically accepted tenet of the psychology literature. The U-shaped relationship that we derive bears some similarity to the Yerkes-Dobson law in the psychology literature (Petri, 1986, Yerkes and Dobson, 1980). As Kaufman (1999, p. 137) put it, "this law states that the relationship between arousal and performance resembles an inverted $\mathrm{U}$ or bell-shaped curve.(...) Although controversy continues among psychologists over the correct specification, domain, and theoretical explanation of the law,(...) the relationship (...) has now been documented in a sufficiently large number of studies with human beings that (it) is one of the few in psychology to be called a 'law' (giving it roughly equal status to the 'law of demand' in economics)."

We now introduce the competitive environment in which the athlete, or salesperson, operates. In this context the influence of the set target $A$ is not constant. Let us say that the strenghth of the challenge, as she perceives it, depends on her environment. We must point out that, in our model, the athletes (or salespersons) are not competing against one another in a given 
contest. One could say they are competing against "nature" or "the market", trying to break an individually imposed record, or reaching a target in a business environment, keeping a wary eye on the competition. We refer to this process as 'emulation'and model it as a function homogenous of degree zero in all goals. That is, if all targets are doubled, the emulation factors for each of the rivals, remain unchanged. Any other assumption than homogeneity would impose an arbitrary scale on the process. One may be tempted to argue that doubling all the targets would have negative effect on the probability of success. While this is a valid argument, the effect of the individual's own goal on their probability of success is already accounted for in our formulation of the probability of success. Hence the setting of higher goals does have a negative effect of its own, but we have kept it separate from the environmental effect of emulation by setting the degree of homogeneity in all goals to zero. To this end we assume the following structure (where, for simplicity, there is only one rival) . It is partly inspired by Tullock's hypothesis about probablity of success in a n-person contest for rents ${ }^{1}$. We take the probability that individual 1 will be successful in reaching target $A_{1}$ while exerting effort $E_{1}$, her ability or self-confidence level being $\lambda_{1}$ and her emulation factor $z_{1}$, which replaces the constant $\kappa$, to be

$$
p_{1}=P\left(E_{1}, A_{1}, \lambda_{1}\right)=\left[\frac{\lambda_{1} E_{1}}{\lambda_{1} E_{1}+A_{1} z_{1}}\right]
$$

Here $E_{1}$ is non-negative, $A_{1}, \lambda_{1}$ and $z_{1}$ are positive real numbers and $z_{1}$ incorporates "emulative factors". As indicated we assume that the emulation factor $z_{1}$ is a function that depends solely on the relative goals set for both

${ }^{1}$ See Tullock (1980), where the probability of success of agent $i$ is

$$
p_{i}=\frac{E_{i}}{E_{i}+\sum_{j \neq i} E_{j}}
$$

See also Hillman and Riley (1989) for a detailed treatment of the case of contests among heterogeneous agents. 
athletes. Therefore if both athletes' goals are doubled, the emulation factor is unchanged. In other words the emulation function is a function of $A_{2} / A_{1} \equiv x$ only and

$$
z_{1} \equiv f(x)
$$

Recall that the athletes are not competing against one another.They are trying to break individually imposed records, or reaching targets in a market environment.

Whether the athlete has set her goal $A_{1}$ or the coach has set it for her, the athlete chooses her effort level $E_{1} \geq 0$, given $A_{1}$ and $z_{1}$. Therefore the problem is as for the isolated individual

$$
\max _{E_{1} \geq 0} W\left(E_{1}\right) \equiv P\left(E_{1}, A_{1}\right) u\left(A_{1}\right)-b E_{1}
$$

Again for simplicity

$$
u\left(A_{1}\right)=A_{1}^{\beta} \text { where } 0<\beta<1
$$

And the first order condition implies

$\lambda_{1} E_{1}^{*}\left(A_{1} ; \lambda_{1}, z_{1}\right)= \begin{cases}z_{1} A_{1}\left[\left(\frac{\bar{A}_{1}}{A_{1}}\right)^{\frac{1-\beta}{2}}-1\right] & \text { if } A_{1} \leq \bar{A}_{1}\left(\lambda_{1}, z_{1}\right) \equiv\left(\frac{\lambda_{1}}{b z_{1}}\right)^{1 /(1-\beta)} \\ 0, & \text { if } A_{1} \geq \bar{A}_{1}\left(\lambda_{1}, z_{1}\right)\end{cases}$

\section{Remarks:}

Since the level of effort chosen by the athlete is a function of goal $A_{1}$, we can define the endogenous probability of success, given the goal $A_{1}$, as follows:

$$
p_{1}\left(A_{1}, \lambda_{1}, z_{1}\right) \equiv P\left(E_{1}^{*}\left(A_{1}, \lambda_{1}, z_{1}\right), A_{1}, \lambda_{1}, z_{1}\right)
$$

Using (3) and (4) we get:

$$
p_{1}=\left[1-\frac{A_{1} z_{1}}{\lambda_{1} E_{1}^{*}+A_{1} z_{1}}\right]
$$


or

$$
p_{1}\left(A_{1}, \lambda_{1}, z_{1}\right)=\left[1-\left(\frac{A_{1}}{\bar{A}_{1}\left(\lambda_{1}, z_{1}\right)}\right)^{(1-\beta) / 2}\right] \text { for } A_{1} \leq \bar{A}_{1}\left(\lambda_{1}, z_{1}\right)
$$

Thus, given $z_{1}$, the higher the goal, the lower is the probability of achieving the target, once the effort level has been chosen.

$$
\begin{gathered}
p_{1}=p\left(A_{1}, \lambda_{1}, z_{1}\right)=\left[1-\left(\frac{A_{1}}{\bar{A}_{1}\left(\lambda_{1}, z_{1}\right)}\right)^{(1-\beta) / 2}\right]=1-A_{1}^{(1-\beta) / 2} \sqrt{\left(\frac{b z_{1}}{\lambda_{1}}\right)} \\
p_{1}=1-A_{1}^{(1-\beta) / 2} \sqrt{\frac{b z_{1}}{\lambda_{1}}} \equiv 1-A_{1}^{(1-\beta) / 2} \sqrt{\frac{b f(x)}{\lambda_{1}}}
\end{gathered}
$$

where $x \equiv A_{2} / A_{1}$.

\section{The Emulation Factor}

When the athlete was on her own we used the following formulation for the probability of success

$$
p_{1}=\frac{\lambda_{1} E_{1}}{\lambda_{1} E_{1}+\kappa A_{1}}
$$

Now that we wish to investigate the effect of emulation on the probability of success, we replace $\kappa$ by $z_{1}$ with

$$
z_{1}=k(1+\alpha h(x)) \equiv f(x), \alpha \geq 0, k>0
$$

with $x=A_{2} / A_{1}$.

If $\alpha=0$ there is no emulation but as $\alpha$ increases the emulative effect becomes stronger. The scaling factor $k$ still has a role in determining the effect of $A_{1}$ on $p_{1}$.

Consider the function $f(x)$ that represents the emulation/intimidation psychological process. When $f(x)=k$, or $\alpha=0$, we have the previous case of no emulation. 
Let us now consider the psychological phenomenon we wish to analyze. It must apply equally to both athletes. That is, whichever way athlete 1 is influenced by athlete 2 having a target twice as big, athlete 2 must be influenced in the same way if athlete 1 has twice her target. Otherwise they would be subject to different psychological processes and our aim is to investigate the one process. It is obvious that different people may react differently to rivalry but our aim here is not to investigate the interesting empirical differences between people in this respect. Our aim is to investigate the consequences of one emulation process, hence some assumption of symmetry - not identity - is required. Suppose for now that the emulation process is entirely symmetrical. This translates into a restriction on $f(x)$. We require that

$$
f(x)=f\left(x^{-1}\right), \text { for all } x>0
$$

as $A_{2} / A_{1}$ and $A_{1} / A_{2}$ have the same emulative effect.

This in turn, with differentiability, implies

$$
f^{\prime}(x)=-x^{-2} f^{\prime}\left(x^{-1}\right) \text { and consequently } f^{\prime}(1)=0
$$

It follows that $f(x)$ cannot be monotone.

If $f(x)$ were to rise initially this would imply that, given $A_{1}$, a lower but increasing $A_{2}$ would decrease $p_{1}$ : athlete 1 would be intimidated by another athlete setting increasing but much lower goals. This seems unreasonable if we wish to consider a process of emulation.We argue that, on the contrary, athlete 1 is stimulated by athlete 2 setting higher and higher goals and thus $f(x)$ is initially decreasing. This must be reversed after $x$ reaches 1 to be consistent with (9); therefore $f(x)$ goes through a minimum at that point. Consequently if the first athlete's goal $A_{1}$ is weighted by $f\left(A_{2} / A_{1}\right)=f(x)$. The second athlete's goal, $A_{2}$, must be weighed by $f\left(A_{1} / A_{2}\right)=f\left(x^{-1}\right)$ since 
we insist that the emulation factor works symmetrically for both athletes. Thus their respective probabilities of success are

$$
p_{1}=\frac{\lambda_{1} E_{1}}{\lambda_{1} E_{1}+f(x) A_{1}} \quad \text { and } \quad p_{2}=\frac{\lambda_{2} E_{2}}{\lambda_{2} E_{2}+f\left(x^{-1}\right) A_{2}}
$$

To sum up we contend that, while $A_{1} \geq A_{2}(x \leq 1)$, an increase in $A_{2}$ -emulation for athlete 1- increases her probability of success (hence $f^{\prime}(x)<0$ for $x<1$ ). But this cannot last forever and at some point an increase in the goal set by a seemingly more confident competitor will have the opposite effect: emulation morphs into intimidation. (There is some empiral evidence that seems to support this hypothesis: marginal students who are admited to elite schools, where they belong to the bottom group of students, do not perform better than equally able students who attend regular schools, where they belong to the best group, Clark(2007)).

This translates into the folowing assumptions on $h(x)$ :

$$
\begin{gathered}
h^{\prime}(x)<0, x<1 \\
h^{\prime}(x)>0, x>1 \\
h(x)=h\left(x^{-1}\right) \\
h(1)=0 \\
h^{\prime}(1)=0 \\
h^{\prime}(x)=-x^{-2} h^{\prime}\left(x^{-1}\right)
\end{gathered}
$$

with also

$$
z_{2}=f\left(x^{-1}\right)=k\left(1+\alpha h\left(x^{-1}\right)\right), \quad x^{-1} \equiv \frac{A_{1}}{A_{2}}
$$


While we have so far assumed that identically able athletes have the strongest emulation effect on eachother's probability of success, this is not necessarily so.

Indeed we argue that the strongst emulation is felt by an athlete when she is confronted by another who aims for a higher goal, but not too much higher. The consequence of this is that the function $f(x)$ will reach its minimum at an $x$ value larger than 1 , say $c>1$. This of course implies that at the $x$ value where athlete 1 is most strongly stimulated by athlete 2 at $x=c$, the converse is not true because athlete 2 faces $c^{-1}$.

The function $f(x)$ therefore must have the typical shape represented in Figure 1, with a minimum at $c>1$. Note that the graph of $f\left(x^{-1}\right)$ against $x^{-1}$ is identical as the two athletes are under the influence of the same emulation process.

This shape is strictly a consequence of assuming that while a competitor sets a goal smaller than $c$ time yours, any increase in it will stimulate you to a better performance -in terms of probability - and that the psychological laws that apply to you also applies to her.

\section{The Coach's Choices and the Nash Equi- librium}

Each coach will set the goal for his athlete, given the goal set by the other coach. Each will maximize

$$
\pi_{i}=p_{i} A_{i}, \quad i=1,2
$$

which represents the expected value of the payoff of his athlete. 


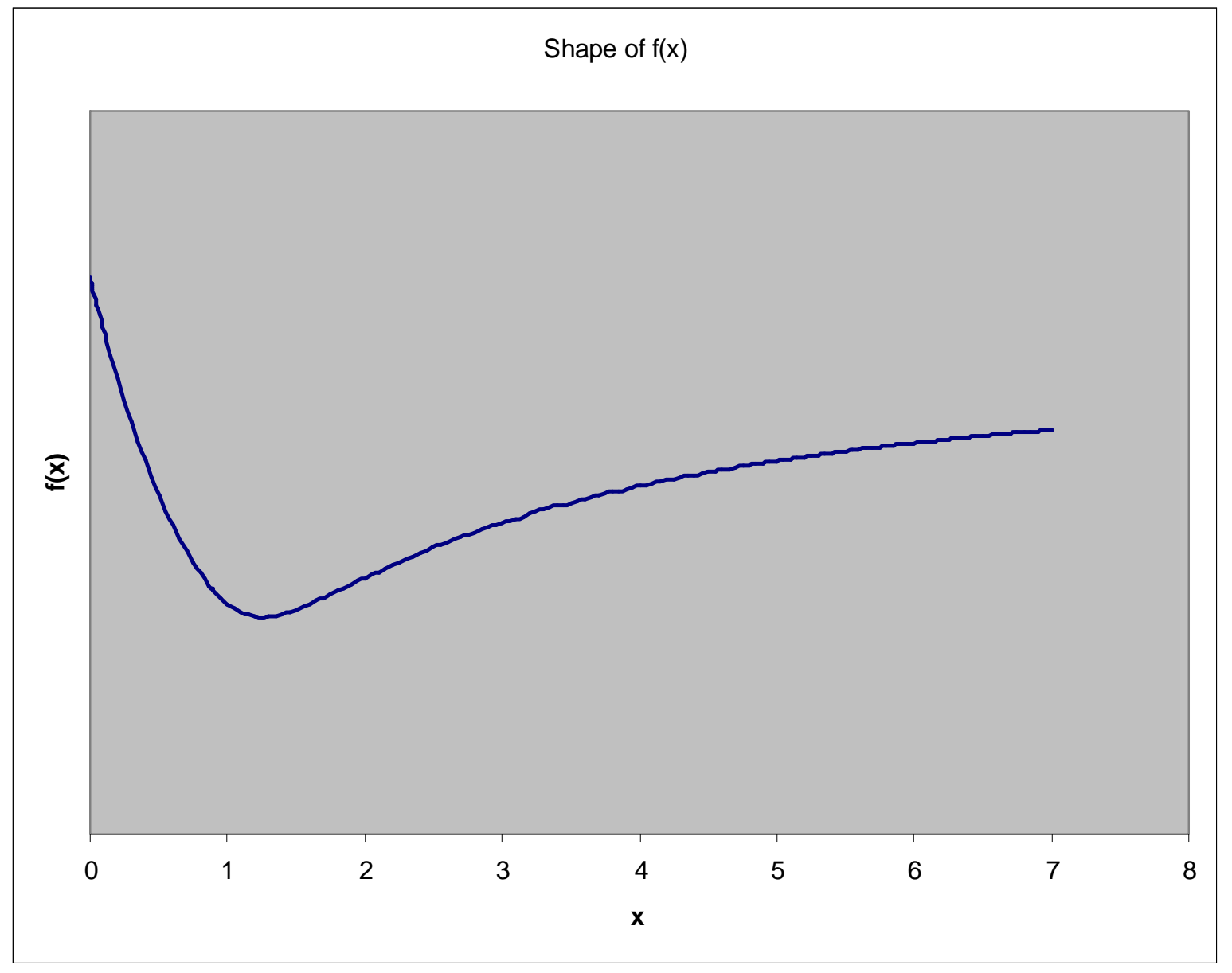


Hence coach 1 chooses $A_{1}$ to maximize

$$
\pi_{1}=p_{1} A_{1}=\left[1-A_{1}^{\gamma} \sqrt{\frac{b f(x)}{\lambda_{1}}}\right] A_{1}
$$

where $\gamma \equiv(1-\beta) / 2>0$. Note that $(1-\beta)$ can be interpreted as the coefficient of relative risk aversion of each athlete.

The first order condition is

$$
G^{1}\left(A_{1}, A_{2}, \lambda_{1}\right) \equiv 1-A_{1}^{\gamma} \sqrt{\frac{b}{\lambda_{1}}}\left[(\gamma+1) \sqrt{f(x)}-\frac{x f^{\prime}(x)}{2 \sqrt{f(x)}}\right]=0
$$

Define

$$
I(x) \equiv\left[(\gamma+1) \sqrt{f(x)}-\frac{x f^{\prime}(x)}{2 \sqrt{f(x)}}\right]
$$

At an interior equilibrium, $I\left(x^{*}\right)>0$, as is clear from the FOC.

The second order condition is

$$
G_{A_{1}}^{1}=-\gamma A_{1}^{\gamma-1} \sqrt{\frac{b}{\lambda_{1}}} I(x)+A_{1}^{\gamma} \sqrt{\frac{b}{\lambda_{1}}} I^{\prime}(x) \frac{A_{2}}{A_{1}^{2}}<0
$$

i.e.

$$
-\gamma A_{1} I(x)+I^{\prime}(x) A_{2}<0
$$

or

$$
I^{\prime}(x)<\gamma x^{-1} I(x)
$$

Similarly, for coach 2 ,

$$
\pi_{2}=p_{2} A_{2}=\left[1-A_{2}^{\gamma} \sqrt{\frac{b f\left(x^{-1}\right)}{\lambda_{2}}}\right] A_{2}
$$

the first order condition is

$$
G^{2}\left(A_{1}, A_{2}, \lambda_{2}\right) \equiv 1-A_{2}^{\gamma} \sqrt{\frac{b}{\lambda_{2}}}\left[(\gamma+1) \sqrt{f\left(x^{-1}\right)}-\frac{x^{-1} f^{\prime}\left(x^{-1}\right)}{2 \sqrt{f\left(x^{-1}\right)}}\right]=0
$$


Define

$$
J(x) \equiv\left[(\gamma+1) \sqrt{f\left(x^{-1}\right)}-\frac{x^{-1} f^{\prime}\left(x^{-1}\right)}{2 \sqrt{f\left(x^{-1}\right)}}\right] \equiv I(y(x))
$$

where $y \equiv 1 / x$.

At an interior equilibrium, $J\left(x^{*}\right)>0$, as is clear from the FOC.

The SOC is

$$
G_{A_{2}}^{2}=-\gamma A_{2}^{\gamma-1} \sqrt{\frac{b}{\lambda_{1}}} J(x)-A_{2}^{\gamma} \sqrt{\frac{b}{\lambda_{2}}} J^{\prime}(x) \frac{1}{A_{1}}<0
$$

ie

$$
-\gamma A_{1} J(x)-J^{\prime}(x) A_{2}<0
$$

or

$$
J^{\prime}(x)+\gamma x^{-1} J(x)>0
$$

Notes: From

$$
I(x)=\frac{1}{\sqrt{f(x)}}\left[(\gamma+1) f(x)-\frac{x}{2} f^{\prime}(x)\right]
$$

and

$$
J(x)=\frac{1}{\sqrt{f\left(x^{-1}\right)}}\left[(\gamma+1) f\left(x^{-1}\right)-\frac{x}{2}^{-1} f^{\prime}\left(x^{-1}\right)\right] \equiv I(y(x))
$$

we get

$$
\left.I^{\prime}(x)=\frac{1}{f(x)}\left\{\left[\left(\gamma+1-\frac{1}{2}\right) f^{\prime}-\frac{x}{2} f^{\prime \prime}\right] f^{1 / 2}-\left[(\gamma+1) f-\frac{x}{2} f^{\prime}\right)\right] \frac{1}{2} f^{-1 / 2} f^{\prime}\right\}
$$

And

$$
\begin{gathered}
J^{\prime}(x)=-I^{\prime}(y) x^{-2} \\
J^{\prime}(x)=\frac{x^{-2}}{f\left(x^{-1}\right)}\left\{-(\gamma+1) f^{\prime}\left(x^{-1}\right)+\frac{x^{-1}}{2} f^{\prime \prime}\left(x^{-1}\right)+\frac{f^{\prime}\left(x^{-1}\right)}{2}\right\} \sqrt{f\left(x^{-1}\right)} \\
+\frac{x^{-2} f^{\prime}\left(x^{-1}\right)}{f\left(x^{-1}\right)}\left[(\gamma+1) f\left(x^{-1}\right)-\frac{x^{-1}}{2} f^{\prime}\left(x^{-1}\right)\right]
\end{gathered}
$$

At a Nash equilibrium, both (16) and (??) hold therefore 


$$
I(x)=R x^{\gamma} J(x)
$$

where $R \equiv \sqrt{\lambda_{1} / \lambda_{2}}$. We may call $R$ the relative confidence of athlete 1 .

If the emulation factor is absent (i.e. $\alpha=0$ ), the Nash equilibrium characterization becomes

$$
\begin{gathered}
1=R x^{\gamma} \\
\frac{A_{2}}{A_{1}}=x=\left(\frac{\lambda_{2}}{\lambda_{1}}\right)^{\gamma / 2}
\end{gathered}
$$

Therefore in the absence of emulation there is a unique Nash equilibrium where the ratio of the goals set is equal to the ratio of the athletes' confidence levels raised to a power equal to a quarter of the athletes's relative risk aversion. It is easy to check that this Nash equilibrium is stable.

It follows that, if the emulation effect is small ( $\alpha$ small) there is a unique stable Nash equilibrium in the space of pure strategies (choosing a goal for one's athlete).

Furthermore, differentiating (24) yields

$$
\frac{d x}{d R}=\frac{x^{\gamma} J(x)}{I^{\prime}(x)-R x^{\gamma}\left[J^{\prime}(x)+\gamma x^{-1} J(x)\right]}
$$

and when $\alpha=0, I(x)=J(x)=\gamma+1$ and

$$
\frac{d x}{d R}=-\frac{x}{\gamma R}<0
$$

Therefore, without any emulation effect an increase in the relative confidence of athlete 1 results in a higher goal ratio in favour of athlete 1. As $\alpha$ increases and the emulation effect becomes stronger the uniqueness and even the existence of the Nash equilibrium in pure startegies cannot be guaranteed.

In order to demonstrate this and to investigate the behaviour of the new equilibrium it suffices to analyze a typical example. 


\section{A Representative Example}

We have argued that the emulation phenomenon as we conceive it must correspond to a function $f(x)$ as illustrated in Figure 1.

One such function is

$$
f(x)=\begin{array}{ll}
k\left(1+\alpha_{1}(x-c)^{2}\right) & \text { if } 0 \leq x \leq c \\
k\left(1+\alpha_{2}\left(x^{-1}-1 / c\right)^{2}\right), & \text { if } c<x
\end{array} .
$$

We set the scales of the confidence and effort costs by setting $b=1 / 1.15$ and $\lambda_{1}=1$ and the strength of the emulation process by setting $k=0.75$, $\alpha_{1}=1$ and $\alpha_{2}=2$. Hence only $\lambda_{2}$ will be variable. We also choose $\beta=0.6$, hence $\gamma=0.2$ and $c=1.25$. This choice of $c$ means that one athlete strives most to emulate another whose goal is $25 \%$ higher. A $10 \%$ higher goal doesn't emulate her as much, nor a 35\% higher goal; a 30\% lower goal provides little emulation. Other parameter choices simply shift the range of solutions without any qualitative impact. The graph in Figure 1 is in fact precisely that of the function in equation 28.

For the moment the reaction function of coach 1 will remain fixed (since we have chosen $\lambda_{1}=1$ ) and only $\lambda_{2}$ varies. It is described by equation (??) and, while it cannot be solved in closed form for $A_{1}^{*}$ in terms of $A_{2}$, it can be traced. It is shown in Figure 2. It seems that, over some subset of the range of $A_{2}$, equation (??) gives us three $A_{1}$ values. Only one corresponds to a maximum of $\pi_{1}$. To elucidate this we trace $\pi_{1}\left(A_{1}\right)$ for selected values of $A_{2}$. These are shown in Figure 3 (where $\left.A_{2}=1\right)$, Figure $4\left(A_{2}^{c}=3.79\right)$ and Figure $5\left(A_{2}=4\right)$. It is evident that equation (??) may select three values of $A_{1}$ when $A_{2}$ is around $A_{2}^{c}$ as shown on Figure 2. The middle value (if one exists)is always a minimum and corresponds to the middle arm of the graph. When $A_{2}$ is smaller than $A_{2}^{c}$, the lowest $A_{1}$ value (below 0.5 ) is a local maximum only while the largest $A_{2}$ value is a global maximum. This is reversed when $A_{2}$ is larger than $A_{2}^{c}$. At the critical value $A_{2}^{c}=3.7$, the profit function has two global maxima as illustrated in Figure 4. 


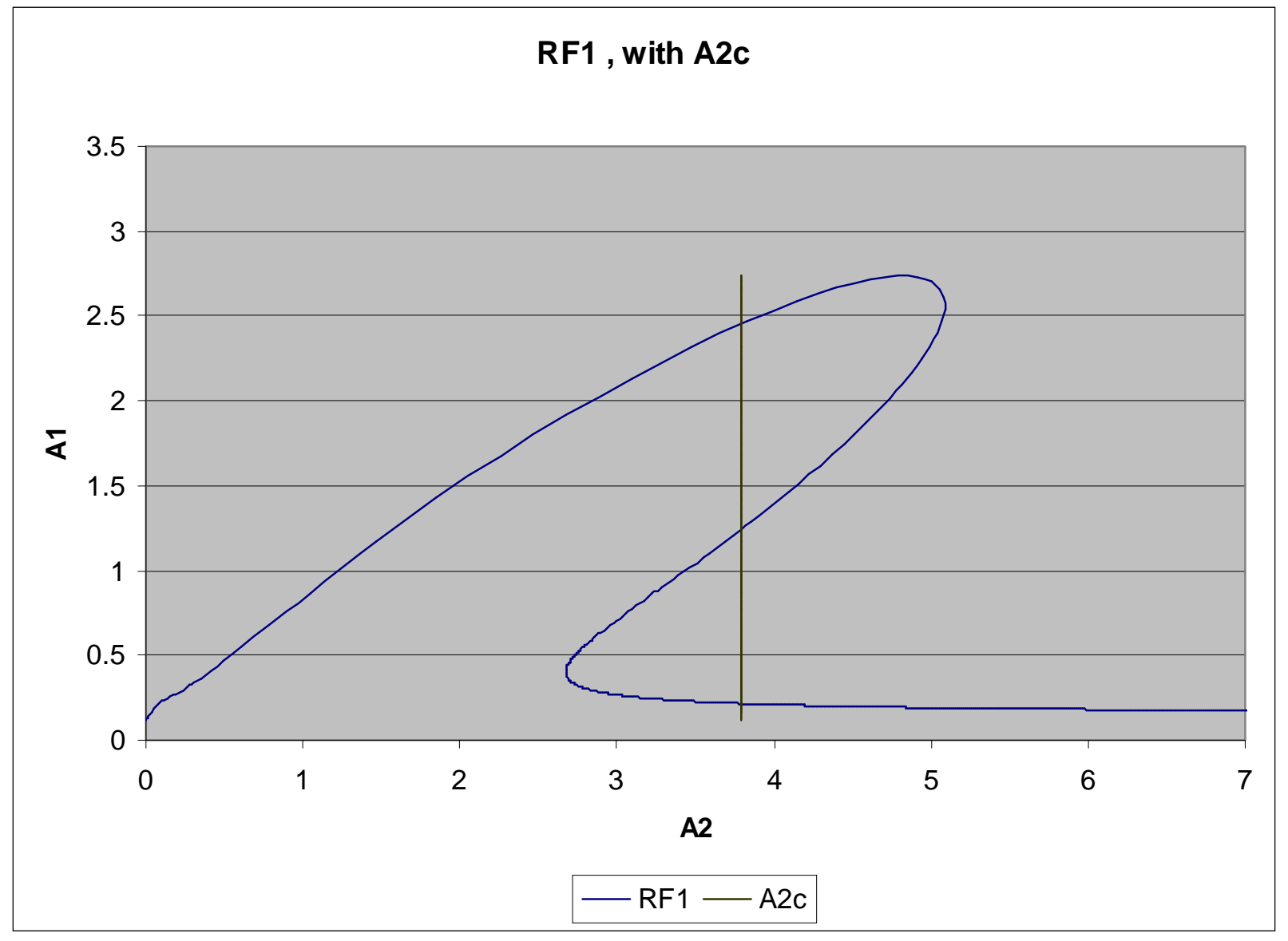




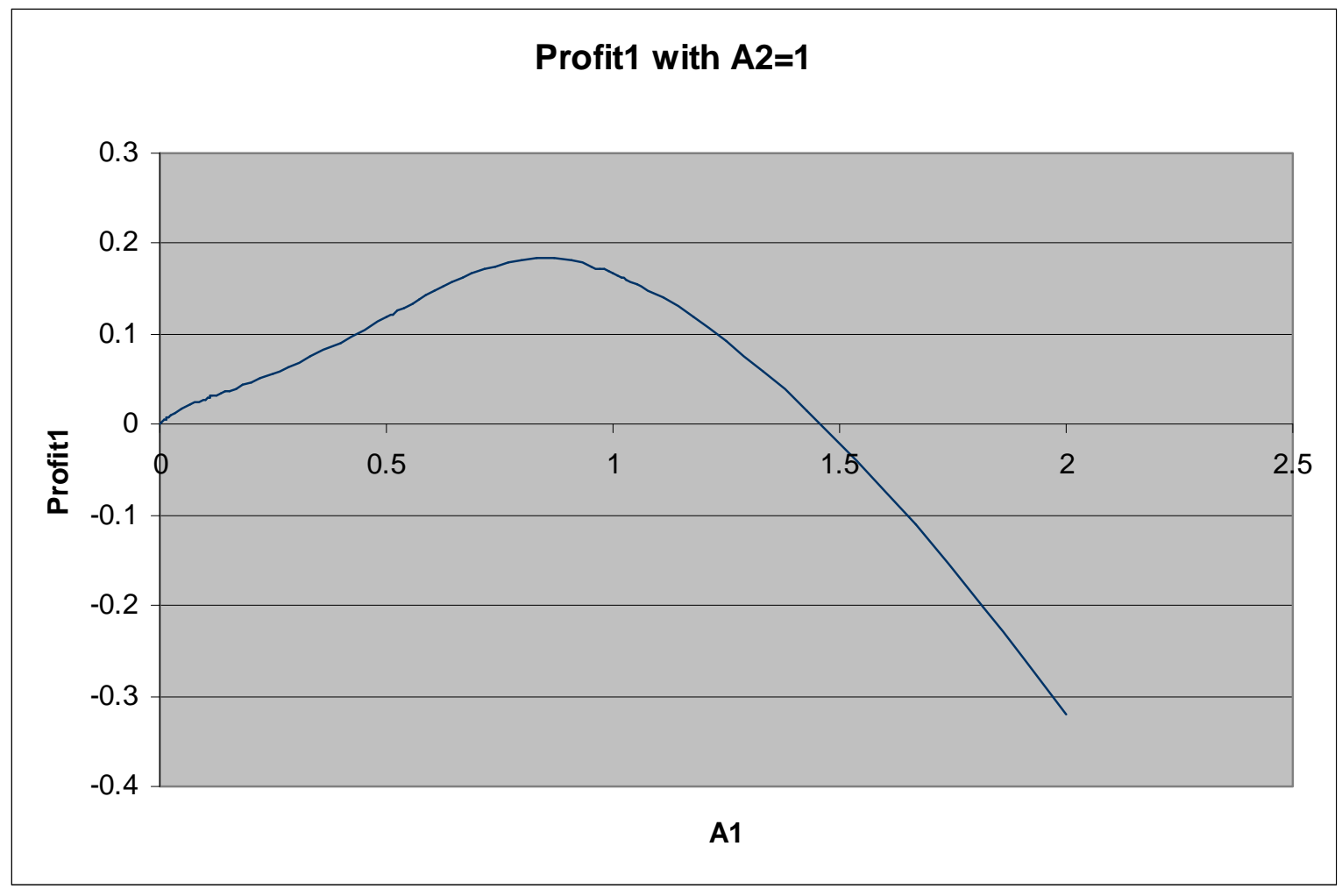




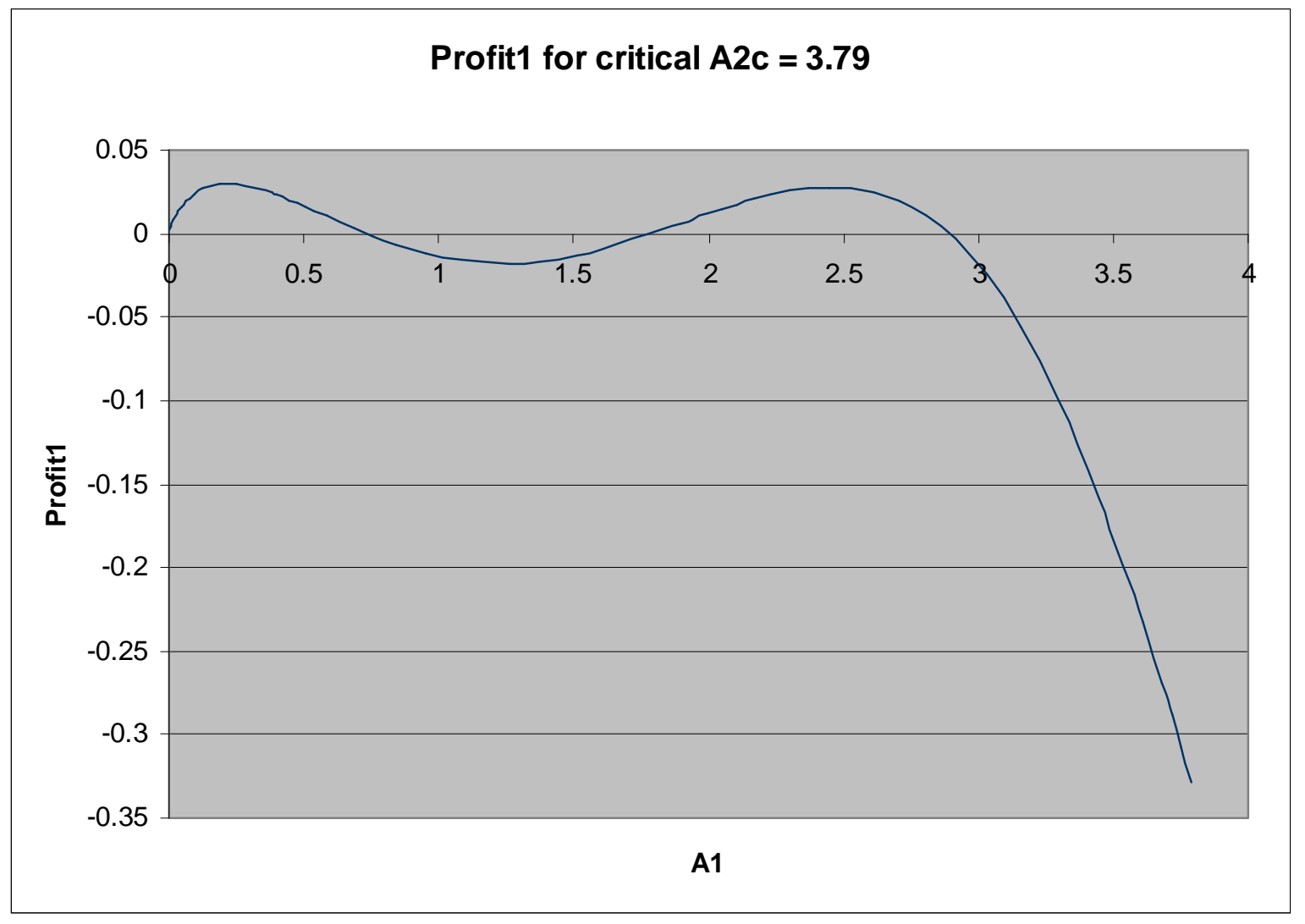




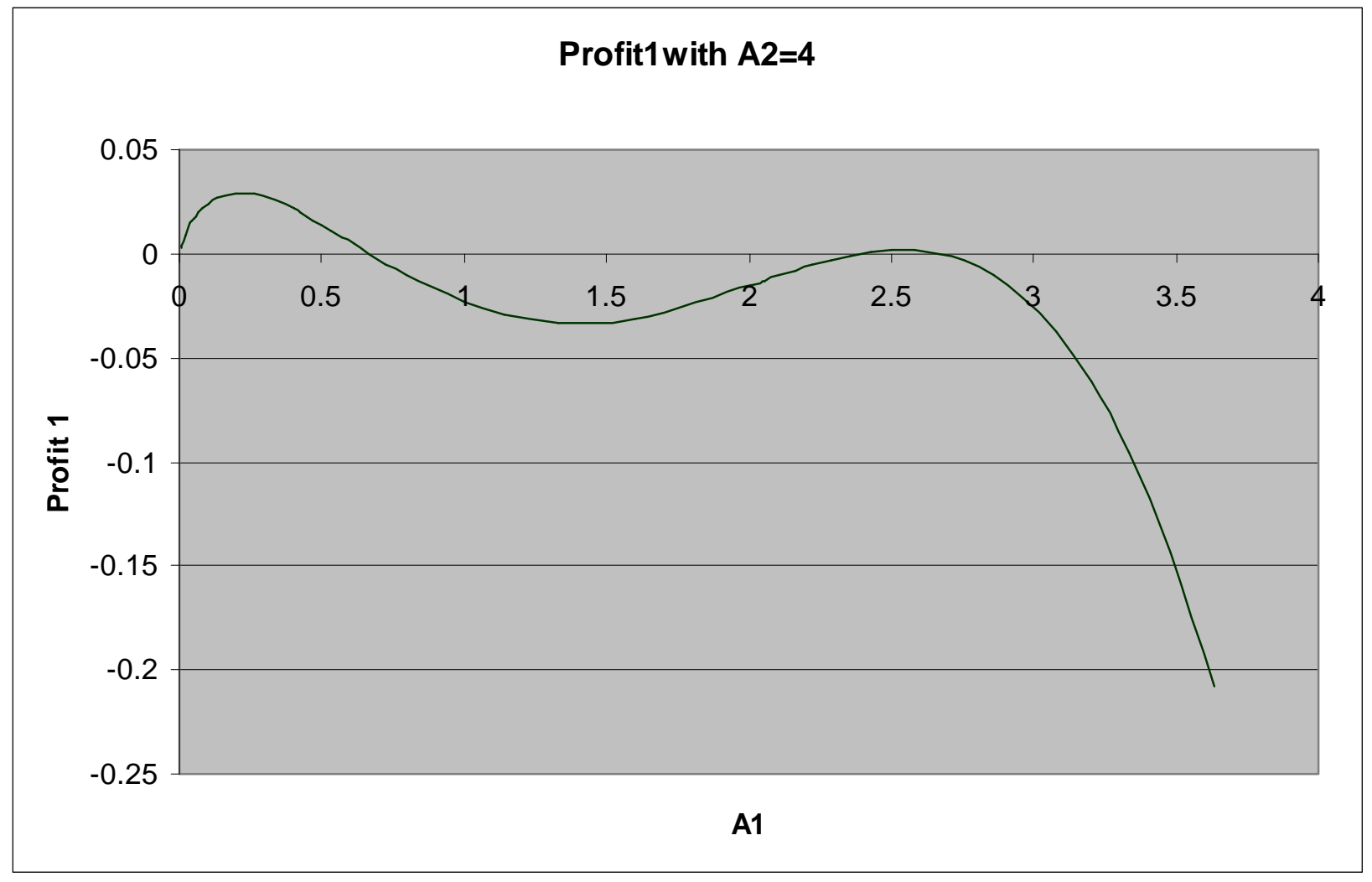


This investigation reveals that the humped shape of the reaction function in Figure 2 is an illusion. The only valid parts of this graph are the uppermost line on the left, until the the critical value $A_{2}^{c}=3.79$ is reached, then the very lowest line as $A_{2}$ increases past $A_{2}^{c}$. The rest of the graph is irrelevant. The "2"-shaped section of Figure 2 that begins on the upper right of the $A_{12}^{c}$ vertical line and ends on its lower left, does not belong to the reaction function: when $A_{2}$ increases past $A_{2}^{c}$, the reaction function of coach 1 exhibits a downward jump discontinuity.

In Figure 6 we have traced the reaction function of coach $1(R F 2)$ when $\lambda_{2}=1$ (as well as the reaction function of coach $2(R F 1$ ), as in Figure 2). The reaction function of coach 2 depends on the value of $\lambda_{2}$ which is allowed to vary. Unsurprisingly the two reaction functions have symmetric shapes and there is a critical value of $A_{1}^{c}$ that sections off parts of the "hump". This $A_{1}^{c}$ value will shift with $\lambda_{2}$. For the time being we focus on $\lambda_{2}>\lambda_{1}=1$. The shape of $R F 2$ is sensitive to the value of $\lambda_{2}$ (since $\lambda_{1}=1$ ). We illustrate this in Figure 7, with $\lambda_{2}=2$, instead of $\lambda_{2}=1$ as it was in Figure 6 . For values of $\lambda_{2}$ much above that range, only the lower arm of $R F 2$ can ever intersect with $R F 1$; the upper arm is much too high. When $\lambda_{2}$ is not too far above 1 , there is an intersection between the lower arm of $R F 2$ and the upper arm of $R F 1$ resulting in a unique stable Nash equilibrium in the approximate range $(0.2,2.7)$, depending on the value of $\lambda_{2}$. One is reprensented in Figure 8, with $\lambda_{2}=3$ which we have labelled an'evensided' equilibrium because the values of $A_{1}^{*}$ and $A_{2}^{*}$ are not very far apart. This equilibrium vanishes for middle values of $\lambda_{2}$, as illustrated in Figure 9 for $\lambda_{2}=3.5$ and another one appears for larger $\lambda_{2}$ values at the intersection of the single visible arm of $R F 2$ and the lower arm of $R F 1$. This results in small values for $A_{1}$ (well below 0.5 ). It is illustrated in Figure 10 with $\lambda_{2}=4.4$. We have labelled this equilibrium 'lopsided' as $A_{2} \gg A_{1}$. The graphs of $R F 2$ have been truncated when the 


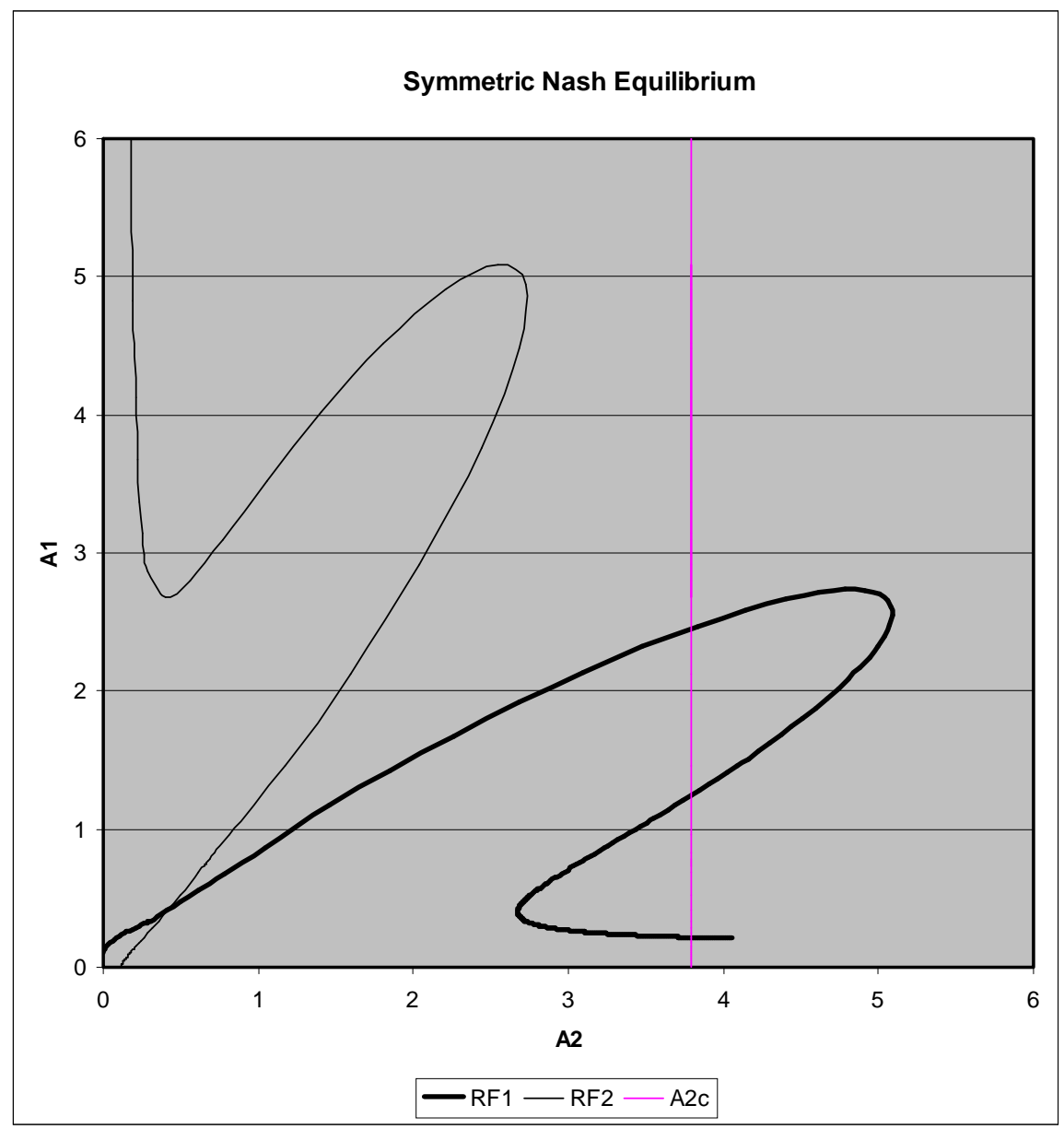

scales required it.

In the middle range of $\lambda_{2}$ values, precisely when $3.3452 \leq \lambda_{2} \leq 4.061$, there is no intersection of $R F 1$ and $R F 2$. Thus there is no Nash equilib- 


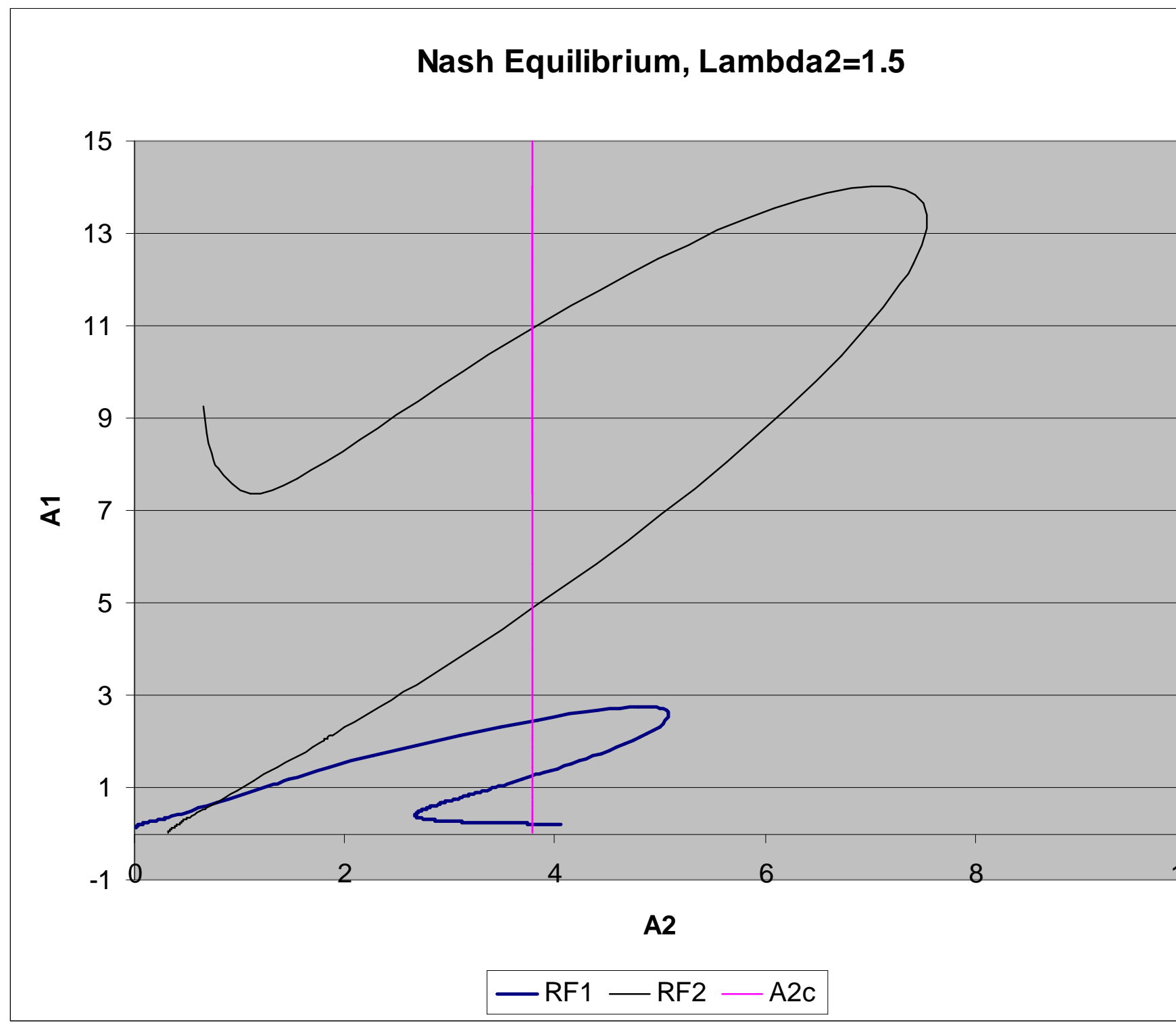




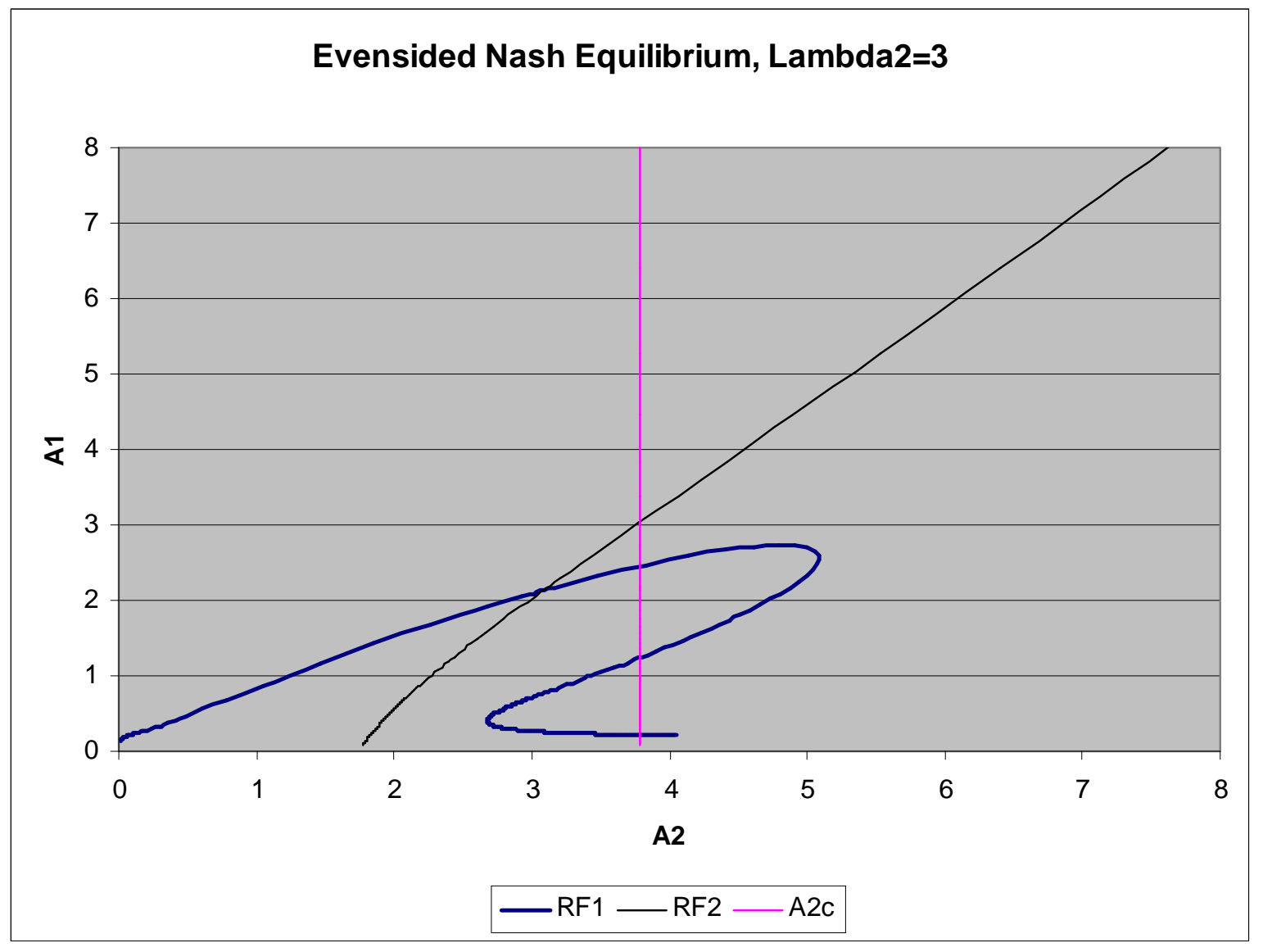




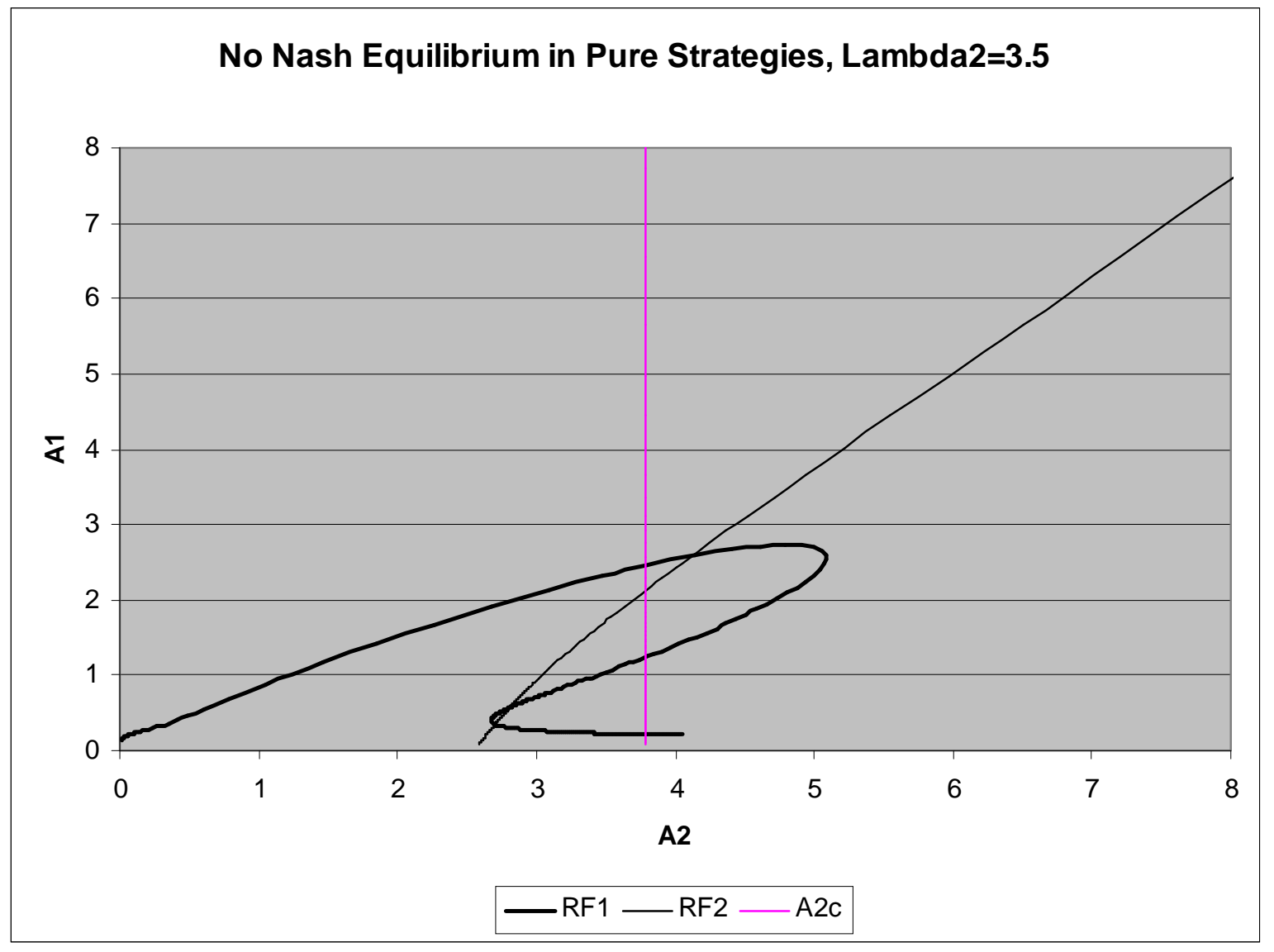




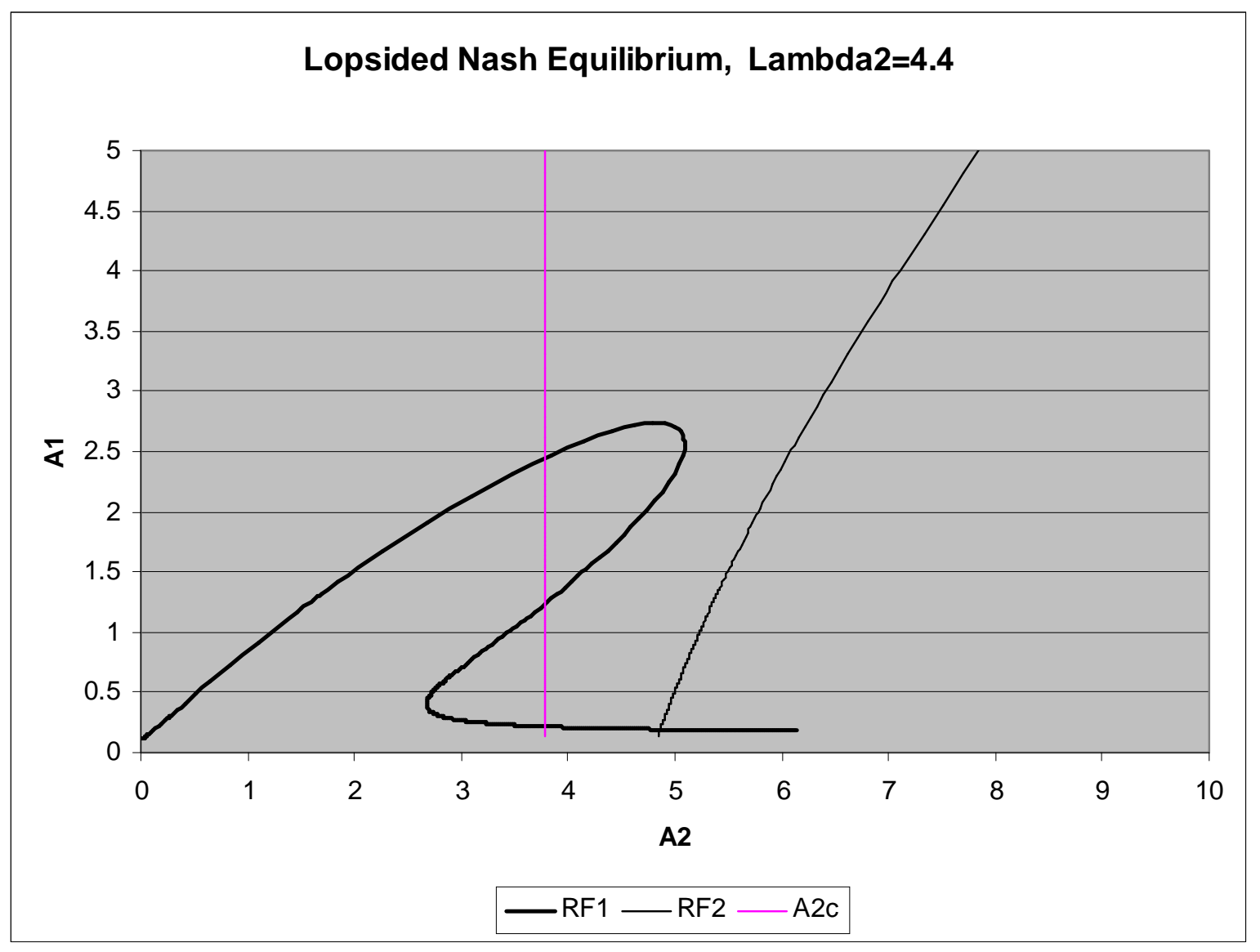


rium in pure srategies. The Nash equilibrium is to be sought among mixed strategies.

We now proceed to characterize these mixed strategy equilibria. Consider Figure 2 and the vertical line marking the critical value of $A_{1}^{c}=3.79$ at which coach 1 is indifferent between playing the highest goal, say $A_{1 H}$, or the lowest goal, say $A_{1 L}$. This is because they correspond to the two $A_{1}$ values yielding identical global maxima for $\pi_{1}$ as shown in Figure 4. Therefore coach 1 must choose $0 \leq q_{1} \leq 1$ and play $A_{1 H}$ with probability $q_{1}$ and $A_{1 L}$ with probability $\left(1-q_{1}\right)$. He will choose $q_{1}$ so that coach 2 's best move is to choose $A_{2}^{c}=3.79$, thereby clinching the Nash equilibrium.

The values of $A_{1 H}$ and $A_{1 L}$ are determined from (??) and $A_{2}^{c}=3.79$. They are $A_{1 H}=2.4556$ and $A_{1 L}=0.216$. With $A_{2}^{c}$ we obtain

$$
x_{H}=1.544 \text { and } x_{L}=17.55 \text {. }
$$

Note that $x_{H}$ corresponds to $A_{1 H}$ and $x_{L}$ to $A_{1 L}$, so $x_{H}$ is the smaller one.

Coach 2 chooses $A_{2}$ to maximize his expected payoff

$$
E\left(\pi_{2}\right)=q_{1} \pi_{2}\left(A_{2}, x_{H}\right)+\left(1-q_{1}\right) \pi_{2}\left(A_{2}, x_{L}\right)
$$

which yields the first-order condition

$$
q_{1}\left[1-A_{2}^{\gamma} \sqrt{\frac{b}{\lambda_{2}}} J\left(x_{H}\right)\right]+\left(1-q_{1}\right)\left[1-A_{2}^{\gamma} \sqrt{\frac{b}{\lambda_{2}}} J\left(x_{L}\right)\right]=0
$$

The value $q_{1}$ that will incite coach 1 to choose $A_{2}=A_{2}^{c}$ is therefore

$$
q_{1}=\frac{-\left(A_{2}^{c}\right)^{-\gamma} \sqrt{\frac{\lambda_{2}}{b}}+J\left(x_{L}\right)}{J\left(x_{L}\right)-J\left(x_{H}\right)}
$$

The values of $q_{1}$ that yields that mixed strategy Nash equilibrium can be tabulated against $\lambda_{2}$ (with $\left.b=1 / 1.15\right)$. These are shown in Table 1 . We 
have purposedly left some $\lambda_{2}$ values that yield $q_{1}$ values outside [0,1]; a single Nash equilibrium in pure strategy clearly prevails then. The $\lambda_{2}$ interval over which a mixed strategy equilibrium prevails is $3.3452 \leq \lambda_{2} \leq 4.061$. Coach 2 always plays $A_{2}^{c}$ in that range. When $\lambda_{2}$ becomes larger coach 1always plays a low $A_{1}$, on the same branch as $A_{1 L}$, and getting smaller as $\lambda_{2}$ keep increasing.

$\begin{array}{ll}\lambda_{2} & q_{1} \\ 3.3 & 1.0668 \\ 3.3452 & 1.000 \\ 3.4 & 0.9201 \\ 3.5 & 0.7755 \\ 3.6 & 0.6331 \\ 3.7 & 0.4925 \\ 3.8 & 0.3538 \\ 3.9 & 0.2170 \\ 4.0 & 0.0819 \\ 4.061 & 0.000 \\ 4.1 & -0.0515\end{array}$

Table 1

Thus we have dealt with the case where $\lambda_{2}>\lambda_{1}=1$. Consider now the reverse situation. From $\left(\lambda_{1}=1, \lambda_{2}=1\right)$ we proceed to increase $\lambda_{1}$. It is obvious that the reverse symmetric situation would be repeated exactly. Therefore on either side of the symmetric equilibrium when $\lambda_{1}=\lambda_{2}=x=1$ we begin with a phase of a still unique and stable Nash equilibrium in pure strategies. When the "moving" $\lambda_{i}$ reaches the critical value of 3.3452 , the other coach plays a mixed strategy as described in Table 1, pinning coach $i$ to $A_{i}^{c}=3.79$. As $\lambda_{i}$ passes 4.061 and keeps increasing, the other coach chooses a low and decreasing goal, while coach $i$ increases his. Therefore the transition to and from mixed strategy equilibria is as smooth as the changes in $\lambda_{i}$.

The above describes all types of solutions when the $\lambda$ 's are above 1 . 
Suppose now that instead of following a separate branch from $\left(\lambda_{1}=\lambda_{2}=\right.$ 1) by letting $\lambda_{2}$ increase, we still keep $\lambda_{1}=1$ but now decrease $\lambda_{2}$ below 1 . We have the same type of solutions and the same phases as when $1=\lambda_{1}<\lambda_{2}$ but, while $R F 1$ remains as we described it, $R F 2$ now shrinks and the scale of the solution (in terms of $A_{1}$ and $A_{2}$ ) also shrinks. When $\lambda_{1}=1$ and $\lambda_{2}<<1$ coaches eventually settle for extremely low goals reflecting one of the athletes' low ability.

We now calculate the values of all the relevant variables at the values of $\lambda_{2}$ for which we illustrated equilibria. See Table 2. We first focus on the results for team 1 , as $\lambda_{2}$ increases from 1 to 2 . Clearly emulation works well at first; the coach sets a higher goal and the athlete tries harder; the coach's profit also increases. However at the higher $\lambda_{2}$ value of 3 , although a high goal is set, the athlete slacks off, the probability of success decreases much and the coach is worse off than at the symmetric equilbrium. When $\lambda_{2}$ is at 4.4, the coach has stopped trying to set high goals, the athlete has stopped trying much at all and profit is abysmal. For team 2 the results are as expected as the athlete gets better and better: her coach sets higher goals, she tries harder and profits increase. Let us now consider the mixed strategy equilibrium. When $\lambda=3.5$, coach 1 plays a mixed strategy equilibrium with $q_{1}=0.7755$. Coach 2 is pinned to a pure strategy, playing the critical $A_{1}^{c}$ value. This resullts in two very different choices for team 1 , but the profit is the same, by construction. The ratios of goal values, hence the $x$ values change by a factor of more than 10 , hence the emulation factor is strongly affected. This is reflected in the $\bar{A}$ values for both athletes. Note that the profit of coach 2 is very high at the High equilibrium. This results in an expected profit of $E\left(\pi_{2}\right)=1.111$ (since $q_{1}=0.7755$ ), the highest in our sample. Clearly coach 2 is very happy when coach 1 plays High because the emulation of athlete 1 contributes to the performance of his athlete. The higher $\lambda_{2}$, the more this process works; however as $\lambda_{2}$ increases, $q_{1}$ decreases 
and this eventually lowers the expected prfit of coach 2 .

$\begin{array}{ccccccccccc}\lambda_{2} & \mathrm{~A}_{1}^{*} & \mathrm{E}_{1}^{*} & \overline{A_{1}} & \mathrm{p}_{1} & \pi_{1} & \mathrm{~A}_{2}^{*} & \mathrm{E}_{2}^{*} & \overline{A_{2}} & \mathrm{p}_{2} & \pi_{2} \\ 1 & \mathbf{0 . 4 1 1} & \mathbf{0 . 1 4 3} & \mathbf{2 . 5 0} & \mathbf{0 . 3 0 3} & \mathbf{0 . 1 2 5} & \mathbf{0 . 4 1 1} & \mathbf{0 . 1 4 2} & \mathbf{2 . 5 0} & \mathbf{0 . 3 0 3} & \mathbf{0 . 1 2 5} \\ \mathbf{2} & \mathbf{1 . 1 1 4} & \mathbf{0 . 1 7 7} & \mathbf{2 . 9 1} & \mathbf{0 . 1 7 5} & \mathbf{0 . 1 9 5} & \mathbf{1 . 3 8 5} & \mathbf{0 . 6 2 1} & \mathbf{1 0 . 4 8} & \mathbf{0 . 3 3 3} & \mathbf{0 . 4 6 1} \\ 3 & \mathbf{2 . 1 2 8} & \mathbf{0 . 0 8 5} & \mathbf{2 . 7 4} & \mathbf{0 . 0 4 9} & \mathbf{0 . 1 0 5} & \mathbf{2 . 0 8 3} & \mathbf{1 . 2 6 4} & \mathbf{2 2 . 9 6} & \mathbf{0 . 3 8 1} & \mathbf{0 . 7 9 4} \\ \mathbf{3 . 5 H} & \mathbf{2 . 4 5 6} & \mathbf{0 . 0 2 2} & \mathbf{2 . 5 6} & \mathbf{0 . 0 1 1} & \mathbf{0 . 2 9 7} & \mathbf{3 . 7 9} & \mathbf{2 . 0 1 6} & \mathbf{3 0 . 7 7} & \mathbf{0 . 3 4 2} & \mathbf{1 . 2 9 7} \\ \mathbf{3 . 5 \mathrm { L }} & \mathbf{0 . 2 1 6} & \mathbf{0 . 0 5 5} & \mathbf{0 . 4 5} & \mathbf{0 . 1 3 8} & \mathbf{0 . 2 9 7} & \mathbf{3 . 7 9} & \mathbf{0 . 9 6 4} & \mathbf{7 . 3 0} & \mathbf{0 . 1 2 3} & \mathbf{0 . 4 6 5} \\ 4.4 & \mathbf{0 . 1 9 3} & \mathbf{0 . 0 5 4} & \mathbf{0 . 4 3} & \mathbf{0 . 1 4 7} & \mathbf{0 . 0 2 8} & \mathbf{4 . 8 6 1} & \mathbf{1 . 8 5 0} & \mathbf{1 2 . 3 9} & \mathbf{0 . 1 7 1} & \mathbf{0 . 8 3 0}\end{array}$

\section{Conclusion}

Using a model of performance based on ability, effort and the effect of goal setting, we have introduced the notion of emulation that accounts for the effect of another participant's goals on the probability of success of an individual. We argued that the individual not only chooses her effort to maximize utility, but also reacts to the goals set by her own coach and the coach of another individual. Specifically the effect of the goal set by her coach on her probability of success is influenced by a function of the ratio of her own goal and that of another individual in a process of emulation, which is the main aspect analyzed in this paper. The structure of this emulation process is discussed at length and results in a situation of strategic interaction between the athletes and guided by their coaches.

This produces a stable Nash equilibrium when the interaction effect is small and an increase in the ability of the more able athlete results in a higher goal ratio in her favour.

Beginning with identically able atheletes, as one athlete's abilty increases, both athletes' set goals are increased but the more able one's increases faster at first. At some critical point the coach of the less able athlete shifts to a mixed strategy that pins the other coach to a single pure strategy. That critical is a well defined value of the goal set for the better athlete, but 
it is reached when the ability of that athlete itself reaches a critical level. Interestingly the payoff for the coach pinned to pure strategy reaches its highest level then. As the better athlete keeps getting better, the coach of the other one reverts to a pure strategy, but one in which he chooses considerably lower goals. Furthermore he sets his goals lower and lower as the other athlete keeps getting better and better, her own coach setting higher and higher goals.

Thus we have demonstrated that this emulation process does encourage the setting of higher goals for some range, but as the discrepancy between athletes passes a critical point, one of the coaches begins setting much lower goals for his athlete in random but precisely calculated fashionand and, after another critical level of discrepancy, always sets very low goals.

Further research may consider introducing ability levels in addtion to set goals in the emulation function.

\section{References}

[2] Beggs, W.D. (1990), Goal Setting in Sports, in J. Graham-Jones and L. Hardy (ed.) Stress and Performance in Sports, John Wiley and Sons, pp 155-91.

[3] Bell, K. F. (1983), Championship Thinking: The Athlete's Guide to Winning Performance in All Sports, Englewood Cliffs, New Jersey, PrenticeHall.

[4] Bentham, Jeremy,(1811) Oeuvres de Jeremy Bentham, Vol 2, Theorie des Peines et Recompenses 131-139, Haumann, Brussels, 
[5] Botterill, C. (1983), Goal Setting for Athletes with Examples from Hockey, in Martin, G.L., Hrycaiko, D. (eds.) Behavior Modification and Coaching: Principles, Procedures, and Research, Springfield, Il., Charles C. Thomas.

[6] Clark, Damon (2007), Selective Schools and Academic Achievement. IZA Discussion Paper, University of Florida.

[7] Dana, James D Jr (2005), Strategic differentiation and strategic Emulation in Games with Uncertainty, The Journal of Industrial Economics, Vol 53, no 3, 417-432.

[8] Brown, Clair (1994), The American Standards of Living, Cambrige, Mass.

[9] Cury, F. and P. Sarrazin, (1993), Motiver les Eleves et Reduire le Stress des Athletes. Analyse des Contributions de la Fixation des Buts a l'Amerioration de la Performance, in J.P. Famose (ed.), Cognition et Performance, Paris, INSEP Publications, 271-300.

[10] Grush, Rick (2002) An introduction to the main principles of emulation: motor control, imagery, and perception, University of California at San Diego.

[11] Hillman, Arye L., and John Riley, 1989, "Politically Contestable Rents and Transfers", Economics and Politics 1: 17-39.

[12] Hardy, L., Maiden, D.S., and K. Sherry (1986), Goal setting and performance anxiety, Journal of Sports Sciences, Vol. 4, 233-4.

[13] Kaufman, B.E. (1999), Emotional Arousal as a Source of Bounded Rationality, Journal of Economic Behavior and Organization 38, 135-144 
[14] Locke, E. A. and G.P. Latham (1990a), A Theory of Goal Setting and Task Performance, Englewood Cliffs, N.J., Prentice-Hall

[15] Locke, E. A. and G. P. Latham (1990b), Work Motivation and Satisfaction: Light at the End of the Tunnel, Psychological Science, Vol 1, 240-6.

[16] Petri, H. (1986) Motivation: Theory and Research, 2nd edition, MIT Press, Cambridge, MA.

[17] Thompson, Doreen E and Russell, J. (2004) The ghost condition: Imitation versus Emulation in young childrens observational learning. Development Psychology, 40 (5). pp. 882-889.

[18] Tullock, G., 1980, Efficient Rent Seeking, in J. M. Buchanan, R. Tollinson and G. Tullock (eds.), Toward a Theory of Rent Seeking Society, Texas A\&M University Press, College Station.

[19] Veblen, Thornstein, (1924) The Theory of the Leisure Class, Allen and Unwin, London

[20] Yerkes, R.M., and J. D. Dobson (1908), The relation od Strength of Stimulus to Rapidity of Habit Formation, Journal of Comparative Neurology and Psychology 18: 459-82. 